Research Article

\title{
Advancing the Understanding of Vitamin D Status in Post-Thyroidectomy Hypocalcemia
}

\author{
Gurdeep Singh $\left(\mathbb{D},{ }^{1}\right.$ Fatima Irshaidat $\mathbb{D}^{\mathrm{D}},{ }^{1}$ Christopher Lau $\mathbb{D}^{\mathrm{D}},{ }^{1}$ Ariel Pedoeem, ${ }^{1}$ \\ Christine Feng $\mathbb{D}$, ${ }^{1}$ Maria Mohammed Fariduddin $\mathbb{D}^{2},{ }^{2}$ Lei Lei Min $\mathbb{D}{ }^{2}$, and Nidhi Bansal $\mathbb{D}^{2}$ \\ ${ }^{1}$ Our Lady of Lourdes Memorial Hospital, 161 Riverside Drive, Binghamton 13905, NY, USA \\ ${ }^{2}$ Upstate University Hospital, 3229 East Genesee Street, Syracuse 13214, NY, USA \\ Correspondence should be addressed to Gurdeep Singh; gurdeep.singh@ascension.org
}

Received 5 February 2021; Revised 21 March 2021; Accepted 25 March 2021; Published 2 April 2021

Academic Editor: Luigi Petramala

Copyright ( $\odot 2021$ Gurdeep Singh et al. This is an open access article distributed under the Creative Commons Attribution License, which permits unrestricted use, distribution, and reproduction in any medium, provided the original work is properly cited.

\begin{abstract}
Background. Post-thyroidectomy hypocalcemia is the most common complication after total thyroidectomy. Studies to examine the role of low vitamin D in increasing post-thyroidectomy hypocalcemia incidence have produced varying results. This study aimed to assess whether vitamin D deficiency increases the risk of post-thyroidectomy hypocalcemia. Methods. This retrospective study involved 244 patients who underwent total thyroidectomy between 2014 and 2019. Patients were divided into two groups based on pre-operative vitamin D levels. Group A and Group B had pre-operative vitamin D (25-hydroxyvitamin D) levels of $\geq 20 \mathrm{ng} / \mathrm{ml}$ and $<20 \mathrm{ng} / \mathrm{ml}$ (reference range for vitamin D is $30-100 \mathrm{ng} / \mathrm{dl}$ ). The effect of vitamin D, gender, body mass index (BMI), and ethnicity on post-operative calcium and PTH levels was analyzed. Results. Post-operative calcium levels for Group A were not statistically different compared to Group B $(8.52 \pm 0.64 \mathrm{mg} / \mathrm{dl}$ vs. $8.45 \pm 0.58 \mathrm{mg} / \mathrm{dl}$ (mean \pm S.D.; $p$ value $=0.352)$. The average post-operative PTH of the two groups did not differ significantly (Group A: $32.4 \pm 27.5 \mathrm{pg} / \mathrm{ml}$; Group B: $34.4 \pm 41.7 \mathrm{pg} / \mathrm{ml} ; p$ value $=0.761)$. Conclusion. Pre-operative vitamin D levels are not predictive of post-thyroidectomy hypocalcemia.
\end{abstract}

\section{Introduction}

Post-thyroidectomy hypocalcemia is the most common complication of thyroidectomy and can cause transient or permanent hypocalcemia $[1,2]$. Several studies examined the relationship between vitamin $\mathrm{D}$ levels and hypocalcemia, but the results were inconsistent. Some studies showed a relationship between pre-operative vitamin $\mathrm{D}$ deficiency and post-thyroidectomy hypocalcemia, whereas others did not [3]. The incidence of thyroid cancer is increasing and vitamin D deficiency is prevalent worldwide [4, 5]. Since the 1970s, thyroid cancer incidence has increased rapidly, although mortality due to thyroid cancer has remained stable [6]. Between 2000 and 2014, 44,537 thyroidectomies were performed to treat thyroid cancer [7]. Hospitals aim to shorten the post-surgical stay for thyroidectomy patients [8], and there is an ongoing trend for these surgeries to be done on an outpatient basis [9].

Based on these factors, determining whether vitamin D levels should be normalized before total thyroidectomy is essential to reduce the risk of morbidity due to symptomatic hypocalcemia and associated prolonged hospital stays.

\section{Materials and Methods}

This was a retrospective study of 244 patients who underwent total thyroidectomy at our institute, Our Lady of Lourdes Memorial Hospital (Binghamton, New York), between 2014 and 2019, and at Upstate University Hospital (Syracuse, New York), between 2014 and 2018.

The study protocol was approved by Our Lady of Lourdes Memorial Lourdes Hospital IRB; informed consent was not obtained due to the retrospective nature of the study.

None of these patients received prophylactic calcitriol or calcium before thyroidectomy. Laboratory results, including levels of calcium and PTH, were obtained within two weeks after thyroidectomy. Post-operative hypocalcemia was defined as a calcium level below the normal laboratory reference range. 
2.1. Inclusion Criteria. All patients who underwent total thyroidectomy and had normal pre-operative calcium and vitamin D levels within six months of surgery were included.

2.2. Exclusion Criteria. Patients who underwent hemithyroidectomy, central or lateral neck dissection, and parathyroidectomy, as well as those who were taking bisphosphonates, were excluded.

\section{Results}

A total of 244 patients that underwent total thyroidectomy between 2014 and 2019 were considered. Of these, 151 had vitamin D (25-hydroxyvitamin D) levels $\geq 20 \mathrm{ng} / \mathrm{ml}$ (Group A), and the remaining 93 patients had low levels $<20 \mathrm{ng} / \mathrm{ml}$ (Group B). The reference range for 25-hydroxyvitamin D was $30-100 \mathrm{ng} / \mathrm{ml}$.

The demographics and biochemical profiles for both groups are presented in Table 1. The average age of patients in Group A was higher than that of Group B (49.4 years old vs. 45.5 years old), and both groups had more females than males $(84.8 \%$ and $78.5 \%$ for Group A and Group B, respectively). The percentage of white patients was $92 \%$ and 75.3\% for Group A and Group, respectively.

Patients in both Group A and Group B were more likely to have benign than cancerous thyroid pathology (Group A: $65.6 \%$ (99) vs. $34.4 \%$ (52); Group B: $60.2 \%$ (56) vs. $39.8 \%$ (37)). Papillary thyroid cancer was present in $90.4 \%$ of cancerous cases in Group A, while 9.6\% had follicular cancer. For Group B, the percentage of papillary thyroid cancer was lower at $78.4 \%$ and follicular cancer was higher at $21.6 \%$.

There was no significant difference between the two groups for the average pre-operative calcium level (Group A: $9.15 \pm 0.58 \mathrm{mg} / \mathrm{dl}$ and Group B: 9.06 \pm 0.48$)$. One-way analysis of variance (ANOVA) carried out using Minitab v.18 also showed no significant difference in the level of postoperative calcium for the two groups (Group A: $8.52 \pm 0.64 \mathrm{mg} / \mathrm{dl}$ and Group B: $8.45 \pm 0.58 \mathrm{mg} / \mathrm{dl}$; $p=0.352$ ). These results indicated no correlation between pre-operative vitamin $\mathrm{D}$ deficiency and post-thyroidectomy hypocalcemia.

Post-operative PTH was available for 143 (58.4\%) of the patients in this study. The average level of post-operative PTH for the two groups was similar (Group A, $32.4 \pm 27.5 \mathrm{pg} / \mathrm{mL}(n=88)$ vs. Group B, $34.4 \pm 41.7 \mathrm{pg} / \mathrm{ml}$ $(n=55) ; p=0.761$; Table 2$)$. Overall, the correlation between post-surgical calcium and post-surgical PTH levels was weak (Pearson correlation coefficient $=0.102 ; p$ value $=0.223$; Figure 1).

We further divided the patient cohort such that Group A had vitamin D levels $\geq 20 \mathrm{ng} / \mathrm{ml}$, Group B levels were $\geq 10 \mathrm{ng} /$ $\mathrm{ml}$ and $<20 \mathrm{ng} / \mathrm{ml}$, and Group $\mathrm{C}$ had levels $<10$ (Table 3). Groups A, B, and C had 151, 79, and 14 patients, respectively. The post-operative calcium levels were similar between the groups $(8.52 \pm 0.64 \mathrm{mg} / \mathrm{dl}, \quad 8.46 \pm 0.6 \mathrm{mg} / \mathrm{dl}, \quad$ and $8.36 \pm 0.46 \mathrm{mg} / \mathrm{dl}$, Groups A, B, and C, respectively; $p=0.448)$, indicating no difference in the incidence of hypocalcemia after thyroidectomy among the groups.
Patients with BMI $<30$ tended to have significantly higher post-operative $\mathrm{PTH}$ values than patients with $\mathrm{BMI}$ $>30(40.13 \mathrm{pg} / \mathrm{ml}$ vs. $27.52 \mathrm{pg} / \mathrm{ml}, p=0.034)$, but the incidence of post-operative hypocalcemia was not significantly affected by body weight $(p=0.477)$.

Post-operative PTH levels among different ethnic groups varied significantly in this study cohort $(p=0.029)$. On average, African Americans tended to have the highest postoperative PTH levels (10 patients, mean value $=45.8 \mathrm{pg} / \mathrm{ml}$; 95\% CI 4.4, 87.2). The 126 patients with ethnicity listed as "White" had a mean value of $33.12 \mathrm{pg} / \mathrm{ml}$ (CI 27.55, 38.70) and the ethnic group listed as other $(n=7)$ had the lowest mean value of $15.83 \mathrm{pg} / \mathrm{ml}$. Although the "White" group tended to have the highest post-operative calcium levels, followed by African Americans and "other," the differences among these groups were not significant ( $p=0.099$ ).

Gender also had no significant effect on post-operative PTH level $(p=0.185)$ and post-operative hypocalcemia $(p=0.997)$.

\section{Discussion}

Hypocalcemia is a well-known post-operative complication of thyroidectomy, but it is primarily transient (less than six months). A meta-analysis by Edafe et al. reported that the incidence of transient and permanent hypocalcemia was $27 \%(19 \%-38 \%)$ and $1 \%(0 \%-3 \%)$, respectively [10].

Post-thyroidectomy hypocalcemia can cause significant morbidity and lengthen hospital stays. Multiple factors can increase the risk of post-surgical hypocalcemia, including autoimmune thyroid disease, substernal goiter, central neck dissection, simultaneous thyroidectomy and parathyroidectomy, prior gastric bypass surgery, previous central neck surgery, and low volume thyroid surgeon [11]. However, whether vitamin $\mathrm{D}$ is predictive of hypocalcemia risk is unclear.

Multiple studies evaluated the role of vitamin D in postthyroidectomy hypocalcemia. However, the inclusion criteria, including the definition of vitamin $\mathrm{D}$ deficiency, the extent of thyroid surgery, and the inclusion of parathyroidectomy or neck dissection, differed among the studies and, in turn, could have produced different outcomes.

Multiple studies reported that vitamin D levels $<20 \mathrm{ng} /$ $\mathrm{ml}$ did not increase the risk of hypocalcemia after total thyroidectomy [12-14]. Meanwhile, Salinger et al. used a vitamin D level $<30 \mathrm{ng} / \mathrm{ml}$, and both Godazandeh et al. and Kim et al. used a vitamin D level $<10 \mathrm{ng} / \mathrm{ml}$. However, despite these different threshold values, none of these studies found vitamin D levels to be predictive of the risk of hypocalcemia after thyroidectomy [15-17].

In a retrospective study on 213 patients who underwent total or completion thyroidectomy, Al-Khatib et al. found that a vitamin D level of $25 \mathrm{nmol} / \mathrm{L}$ was predictive of postoperative hypocalcemia [18]. The more extensive metaanalysis by Edafe et al. found similar results [10].

Our study analyzed the data using vitamin D thresholds of $\geq 20 \mathrm{ng} / \mathrm{ml}$ and $\leq 20 \mathrm{ng} / \mathrm{ml}$ to group the patients. Consistent with some earlier studies, we also found no relationship between vitamin $\mathrm{D}$ deficiency and post- 
TABLE 1: Patient characteristics.

\begin{tabular}{|c|c|c|c|}
\hline & Group A, Vit-D $>=20 \mathrm{ng} / \mathrm{ml}$ mean $(N) \pm \mathrm{SD}$ & Group B, Vit-D $<20 \mathrm{ng} / \mathrm{ml}$ & $p$ value \\
\hline Age & $49.4(138) \pm 17.3$ & $45.5(86) \pm 14.4$ & 0.072 \\
\hline $\begin{array}{l}\text { Gender } \\
\text { Male } \\
\text { Female }\end{array}$ & $\begin{array}{c}15.2 \%(20) \\
84.8 \%(128)\end{array}$ & $\begin{array}{l}21.5 \%(20) \\
78.5 \%(73)\end{array}$ & 0.363 \\
\hline $\begin{array}{l}\text { Ethnicity } \\
\text { White } \\
\text { African American } \\
\text { Other }\end{array}$ & $\begin{array}{c}92 \%(139) \\
4 \%(6) \\
4 \%(6) \\
\end{array}$ & $\begin{array}{c}75.3 \%(70) \\
16.1 \%(15) \\
8.6 \%(8) \\
\end{array}$ & 0.003 \\
\hline $\begin{array}{l}\text { BMI } \\
\text { Thyroid pathology } \\
\text { Percentage }(N) \\
\text { Cancerous } \\
\text { Benign }\end{array}$ & $\begin{array}{l}34.4 \%(52) \\
65.6 \%(99)\end{array}$ & $\begin{array}{l}39.8 \%(37) \\
60.2 \%(56)\end{array}$ & 0.044 \\
\hline $\begin{array}{l}\text { Thyroid cancer } \\
\text { Percentage }(N) \\
\text { Papillary } \\
\text { Follicular }\end{array}$ & $\begin{array}{c}90.4 \%(47) \\
9.6 \%(5)\end{array}$ & $\begin{array}{c}78.4 \%(29) \\
21.6 \%(8) \\
\end{array}$ & 0.076 \\
\hline $\begin{array}{l}\text { Vitamin D ng/ml } \\
\text { Pre-op calcium mg/dl } \\
\text { Post-op calcium mg/dl } \\
\text { Post-op PTH pg/ml }\end{array}$ & $\begin{array}{c}30.85(151) \pm 9.48 \\
9.15(151) \pm 0.58 \\
8.52(151) \pm 0.64 \\
32.4(88) \pm 27.5\end{array}$ & $\begin{array}{l}13.47(93) \pm 4.3 \\
9.06(93) \pm 0.48 \\
8.45(93) \pm 0.58 \\
34.4(55) \pm 41.7\end{array}$ & $\begin{array}{c}\text { Not applicable } \\
0.168 \\
0.352 \\
0.761\end{array}$ \\
\hline
\end{tabular}

TABle 2: Relationship of post-surgical PTH and Ca levels with potential risk factors for post-operative hypocalcemia.

\begin{tabular}{|c|c|c|c|c|}
\hline Factor; level & & & $\begin{array}{l}\text { Post-surgical PTH (pg/ } \\
\mathrm{ml})\end{array}$ & Post-surgical Ca (mg/dl) \\
\hline \multirow{3}{*}{ Pre-surgical vitamin D ng/ml } & & $p$ value & 0.761 & 0.352 \\
\hline & $D<20 \mathrm{ng} / \mathrm{ml}$ & Mean $(N)$ (confidence interval) & $34.35(55)(23.08,45.63)$ & $8.45(93)(8.3256,8.5647)$ \\
\hline & $D>=20 \mathrm{ng} / \mathrm{ml}$ & Mean $(N)$ (confidence interval) & $32.42(88)(26.58,38.25)$ & $8.52(151)(8.4168,8.6216)$ \\
\hline \multirow{4}{*}{ Ethnicity } & & $p$ value & 0.029 & 0.099 \\
\hline & African American & Mean $(N)$ (confidence interval) & $45.8(10)(4.4,87.2)$ & $8.45(21)(8.109,8.786)$ \\
\hline & Other & Mean $(N)$ (confidence interval) & $15.83(7)(3.57,28.09)$ & $8.08(14)(7.665,8.492)$ \\
\hline & White & Mean $(N)$ (confidence interval) & $33.12(126)(27.55,38.70)$ & $8.52(209)(8.4428,8.6031)$ \\
\hline \multirow{3}{*}{ Gender } & & $p$ value & 0.185 & 0.997 \\
\hline & Female & Mean $(N)$ (confidence interval) & $30.74(121)(25.62,35.87)$ & $8.45(201)(8.4040,8.5780)$ \\
\hline & Male & Mean $(N)$ (confidence interval) & $46.5(22)(23.1,69.8)$ & $8.49(43)(8.3134,8.6680)$ \\
\hline \multirow{3}{*}{ BMI } & & $p$ value & 0.034 & 0.477 \\
\hline & Normal BMI $<30$ & Mean $(N)$ (confidence inte & $40.13(64)(29.73,50.54)$ & $8.46(109)(8.3394,8.5824)$ \\
\hline & High $\mathrm{BMI}>=30$ & Mean $(N)$ (confidence interval) & $27.52(79)(22.13,32.90)$ & $8.52(133)(8.4159,8.6202)$ \\
\hline
\end{tabular}

thyroidectomy hypocalcemia. Considering a lower threshold of $<10 \mathrm{ng} / \mathrm{ml}$ also showed no relationship with the risk of post-thyroidectomy hypocalcemia.

Our study's results align with those reported by Griffin et al., Salinger et al., Godazandeh et al., and Cherian et al., but the sample size was $<150$ in these studies compared to 244 in our study. Another strength of our study is that more than one surgeon performed total thyroidectomies.

Our study's limitations are its retrospective nature and the availability of post-operative PTH values for just over half $(143 / 244 ; 58.4 \%)$ of the patients. Another limitation is that we evaluated the calcium and PTH within 2 weeks after total thyroidectomy only, so this study does not differentiate between temporary or permanent hypoparathyroidism.

A significant body of data indicates that prophylactic use of calcium or vitamin D can decrease the risk of post-operative hypocalcemia [19]. In a review of 15 studies, Gregory et al. found that perioperative vitamin $\mathrm{D}$ and calcium supplements effectively prevented both laboratory and symptomatic hypocalcemia [20]. Furthermore, a metaanalysis by Xing et al. reported that post-operative use of calcium and vitamin $\mathrm{D}$ had a better preventative effect than calcium alone [21].

In the present study, we found that higher BMI $(>30)$ could be related to a significantly lower PTH level but saw no relationship between BMI and post-operative hypocalcemia. A prospective study by Final et al. reported a lower incidence of permanent hypoparathyroidism (1.05 vs. $1.38 \%)$ in patients with $\mathrm{BMI}<25$ compared to those with $\mathrm{BMI} \geq 25$, but this difference was not statistically significant [22].

Moreover, ethnicity did seem to affect the post-operative level of PTH, but not post-operative calcium, although a larger sample size is needed to confirm this relationship. 


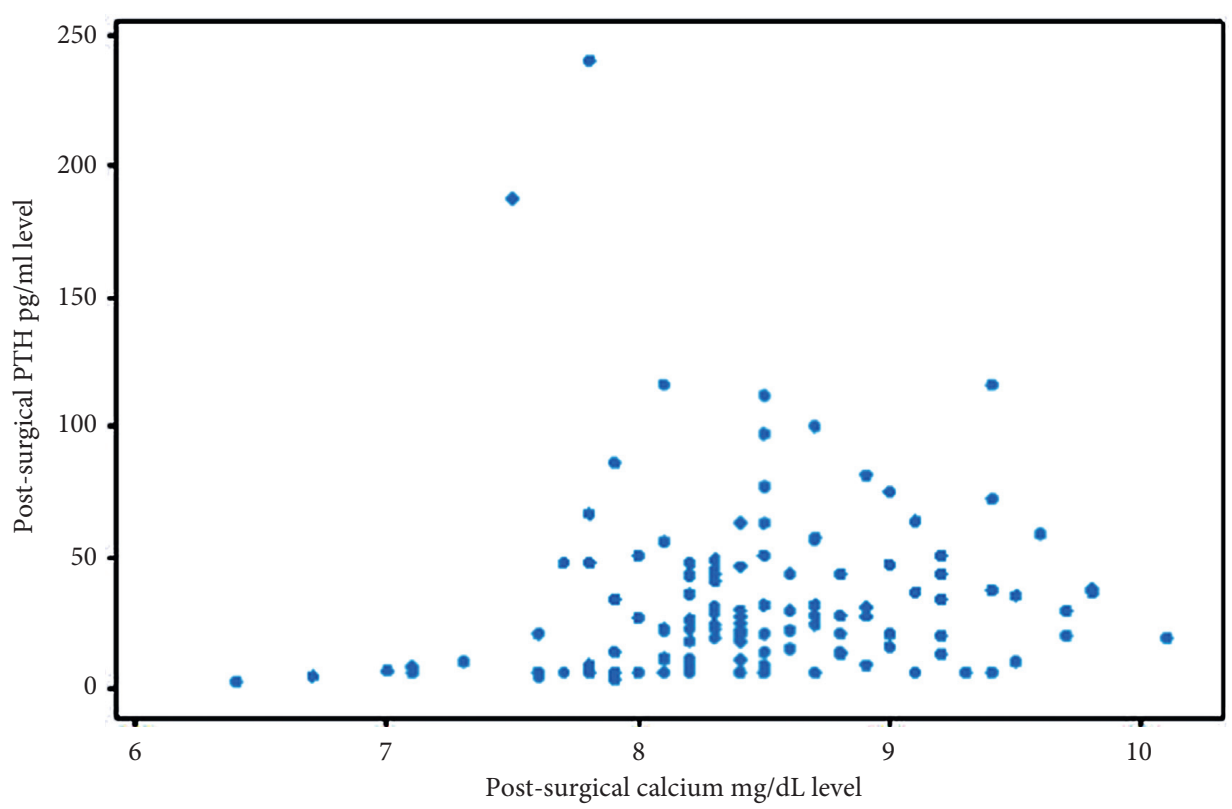

FIGURE 1: Pearson correlation coefficient between post-surgical calcium and post-surgical parathyroid hormone was 0.102 indicating a weak correlation.

TABLE 3: Relationship between pre-operative vitamin D levels and post-operative hypocalcemia and PTH.

\begin{tabular}{|c|c|c|c|c|}
\hline & Group A, Vit-D $>=20 \mathrm{ng} / \mathrm{ml}$ & Group B, Vit-D $<20 \mathrm{ng} / \mathrm{ml}$ & Group $\mathrm{C}$, Vit-D $<10 \mathrm{ng} / \mathrm{ml}$ & $p$ value \\
\hline rocalcemia & $8.52 \pm 0.64 \mathrm{mg} / \mathrm{dl}(151)$ & $8.46 \pm 0.6 \mathrm{mg} / \mathrm{dl}(79)$ & $8.36 \pm 0.46 \mathrm{mg} / \mathrm{dl}(14)$ & 0.448 \\
\hline Post-operative PTH & $32.42 \pm 27.53 \mathrm{pg} / \mathrm{ml}(88)$ & $25.47 \pm 19.4 \mathrm{pg} / \mathrm{ml}(46)$ & $79.8 \pm 82.8 \mathrm{pg} / \mathrm{ml}(9)$ & 0.07 \\
\hline Age (yr) & $49.7 \pm 16.9(138)$ & $45.4 \pm 14.1(73)$ & $46.3 \pm 16.7(13)$ & \\
\hline
\end{tabular}

Perioperative supplements with vitamin $\mathrm{D}$ and calcium appear to prevent symptomatic hypercalcemia effectively. However, there is insufficient evidence to indicate that pre-operative vitamin $\mathrm{D}$ deficiency is a risk factor for post-operative hypocalcemia.

\section{Conclusion}

Vitamin D levels were not predictive of post-thyroidectomy hypocalcemia at our institution. Correcting vitamin D levels before total thyroidectomy to reduce the risk of morbidity due to symptomatic hypocalcemia and prolonged hospital stays is unnecessary. Previous studies on the association of vitamin $\mathrm{D}$ with post-operative hypocalcemia have produced varying results. These differences could be due to their retrospective nature and involvement of only one center and the multiple risk factors that contribute to the risk of hypocalcemia. Consideration of all these factors in retrospective studies can be challenging. Thus, a multicenter, randomized control trial is needed to determine whether pre-operative normalization of vitamin $\mathrm{D}$ should be recommended before total thyroidectomy.

\section{Data Availability}

The dataset generated during the current study is available from the corresponding author on reasonable request.

\section{Conflicts of Interest}

The authors declare that they have no conflicts of interest.

\section{Acknowledgments}

We thank Our Lady of Lourdes Memorial Hospital and Lake Erie College of Osteopathic Medicine for their support. This research study was supported by Lake Erie College of Osteopathic Medicine (LECOM) and Lake Erie Consortium for Osteopathic Medical Training (LECOMT) (total amount: \$5000; grant no: J2018.37).

\section{References}

[1] M. A. Cannizzaro, S. Lo Bianco, M. C. Picardo, D. Provenzano, and A. Buffone, "How to avoid and to manage post-operative complications in thyroid surgery," Updates in Surgery, vol. 69, no. 2, pp. 211-215, 2017.

[2] E. Chahardahmasumi, R. Salehidoost, M. Amini et al., "Assessment of the early and late complication after thyroidectomy," Advanced Biomedical Research, vol. 8, p. 14, 2019.

[3] G. Manzini, F. Malhofer, and T. Weber, "Can preoperative vitamin D deficiency predict postoperative hypoparathyroidism following thyroid surgery?" Langenbeck's Archives of Surgery, vol. 404, no. 1, pp. 55-61, 2019.

[4] B. R. Roman, L. G. Morris, and L. Davies, "The thyroid cancer epidemic, 2017 perspective," Current Opinion in Endocrinology \& Diabetes and Obesity, vol. 24, no. 5, pp. 332-336, 2017. 
[5] M. F. Holick, "The vitamin D deficiency pandemic: approaches for diagnosis, treatment and prevention," Reviews in Endocrine and Metabolic Disorders, vol. 18, no. 2, pp. 153-165, 2017.

[6] C. M. Kitahara and J. A. Sosa, "The changing incidence of thyroid cancer," Nature Reviews Endocrinology, vol. 12, no. 11, pp. 646-653, 2016.

[7] B. C. James, L. Timsina, R. Graham, P. Angelos, and D. A. Haggstrom, "Changes in total thyroidectomy versus thyroid lobectomy for papillary thyroid cancer during the past 15 years," Surgery, vol. 166, no. 1, pp. 41-47, 2019.

[8] S. Vrabec, S. C. Oltmann, N. Clark, H. Chen, and R. S. Sippel, "A short-stay unit for thyroidectomy patients increases discharge efficiency," Journal of Surgical Research, vol. 184, no. 1, pp. 204-208, 2013.

[9] G. H. Sun, S. DeMonner, and M. M. Davis, "Epidemiological and economic trends in inpatient and outpatient thyroidectomy in the United States, 1996-2006," Thyroid, vol. 23, no. 6, pp. 727-733, 2013.

[10] O. Edafe, R. Antakia, N. Laskar, L. Uttley, and S. P. Balasubramanian, "Systematic review and meta-analysis of predictors of post-thyroidectomy hypocalcaemia," British Journal of Surgery, vol. 101, no. 4, pp. 307-320, 2014.

[11] L. A. Orloff, S. M. Wiseman, V. J. Bernet et al., "American thyroid association statement on postoperative hypoparathyroidism: diagnosis, prevention, and management in adults," Thyroid, vol. 28, no. 7, pp. 830-841, 2018.

[12] T. P. Griffin, M. S. Murphy, and P. Sheahan, "Vitamin D and risk of postoperative hypocalcemia after total thyroidectomy," JAMA Otolaryngology-Head \& Neck Surgery, vol. 140, no. 4, pp. 346-351, 2014.

[13] A. J. Cherian, S. Ponraj, S. M. Gowri et al., "The role of vitamin D in post-thyroidectomy hypocalcemia: still an enigma," Surgery, vol. 159, no. 2, pp. 532-538, 2016.

[14] X. Wang, J. Zhu, F. Liu, Y. Gong, and Z. Li, "Preoperative vitamin $\mathrm{D}$ deficiency and postoperative hypocalcemia in thyroid cancer patients undergoing total thyroidectomy plus central compartment neck dissection," Oncotarget, vol. 8, no. 44, pp. 78113-78119, 2017.

[15] E. M. Salinger and J. T. Moore, "Perioperative indicators of hypocalcemia in total thyroidectomy: the role of vitamin D and parathyroid hormone," The American Journal of Surgery, vol. 206, no. 6, pp. 876-882, 2013.

[16] G. Godazandeh, Z. Kashi, F. Godazandeh, P. Tayebi, and A. Bijani, "Influence of thyroidectomy on postoperative serum calcium level regarding serum vitamin D status. A prospective study," Caspian Journal of Internal Medicine, vol. 6, no. 2, pp. 72-76, 2015.

[17] W. W. Kim, S.-H. Chung, E. J. Ban et al., "Is preoperative vitamin D deficiency a risk factor for postoperative symptomatic hypocalcemia in thyroid cancer patients undergoing total thyroidectomy plus central compartment neck dissection?" Thyroid, vol. 25, no. 8, pp. 911-918, 2015.

[18] T. Al-Khatib, A. M. Althubaiti, A. Althubaiti, H. H. Mosli, R. O. Alwasiah, and L. M. Badawood, "Severe vitamin D deficiency: a significant predictor of early hypocalcemia after total thyroidectomy," Otolaryngology-Head and Neck Surgery, vol. 152, no. 3, pp. 424-431, 2015.

[19] A. Alhefdhi, H. Mazeh, and H. Chen, "Role of postoperative vitamin $\mathrm{D}$ and/or calcium routine supplementation in preventing hypocalcemia after thyroidectomy: a systematic review and meta-analysis," The Oncologist, vol. 18, no. 5, pp. 533-542, 2013.
[20] A. Grzegory and L. Pomorski, "Perioperative calcium and vitamin D supplementation in patients undergoing thyroidectomy-literature review," Polski Przeglad Chirurgiczny, vol. 90, pp. 46-50, 2018.

[21] T. Xing, Y. Hu, B. Wang, and J. Zhu, "Role of oral calcium supplementation alone or with vitamin $\mathrm{D}$ in preventing postthyroidectomy hypocalcaemia: a meta-analysis," Medicine (Baltimore), vol. 98, Article ID e14455, 2019.

[22] J. B. Finel, S. Mucci, F. Branger et al., "Thyroidectomy in patients with a high BMI: a safe surgery?" European Journal of Endocrinology, vol. 171, no. 1, pp. 99-105, 2014. 